\title{
Perspectives of gold nanoparticles and their applications in pancreatic cancer (Review)
}

\author{
ANAMARIA MAGDALENA TOMŞA ${ }^{1}$, ANDREEA LIANA RĂCHIŞAN ${ }^{1}$, \\ ANDREEA ALEXANDRA ALDEA ${ }^{1 *}$ and LORENA CIUMĂRNEAN ${ }^{2 *}$ \\ ${ }^{1}$ Department No. 9 Mother and Child, 2nd Clinic of Pediatrics and ${ }^{2}$ Department of Internal Medicine \\ IV, 'Iuliu Haţieganu’ University of Medicine and Pharmacy, 400012 Cluj-Napoca, Romania
}

Received September 16, 2020; Accepted October 16, 2020

DOI: $10.3892 / \mathrm{etm} .2021 .9689$

\begin{abstract}
Nanoparticles (NPs) represent a major point of interest in the scientific field, with an increasing number of studies revealing promising results. Nano-oncology is a relatively new area of research that continues to expand, revealing new perspectives in both diagnosing and treating cancer. Treating pancreatic cancer (PC) remains a major challenge, with modest positive results, thus an increasing number of studies have focused on this disease. Out of all the NPs that have been used in experimental studies, gold NPs (GNPs) appear to be the most efficient, with little systemic toxicity. This review aims to summarize the latest studies that reveal the effects that GNPs have on PC cells, focusing on different ways in which they can be used to diagnose this disease, to induce apoptosis or cause cytotoxicity in cancer cells. Although literature has limited data concerning this specific topic, the results are promising. However more studies are required until GNPs can be used in clinical practice.
\end{abstract}

\section{Contents}

1. Introduction

2. Materials and methods

3. Overview of GNPs

4. GNPs used in the treatment of PC

5. GNPs and targeted drug therapy in PC

6. Other perspectives on GNPs and PC

7. Conclusions

Correspondence to: $\mathrm{Dr}$ Andreea Liana Răchişan, Department No. 9 Mother and Child, 2nd Clinic of Pediatrics, 'Iuliu Haţieganu' University of Medicine and Pharmacy, Crisan 3, 400012 Cluj-Napoca, Romania

E-mail: andreea_rachisan@yahoo.com

*Contributed equally

Key words: gold nanoparticles, pancreatic cancer, theranostic, targeted drug delivery, chemotherapy, quantum dots

\section{Introduction}

Malignancies represent a major health issue worldwide, with outcomes depending on numerous factors including the genetical background, environmental triggers, the tumor stage at the time of diagnosis, the clinical response to treatment, but most importantly, the type of tumor (1). One of the most aggressive cancers that remains difficult to treat, with a 5 -year survival rate less than 5\%, is pancreatic cancer (PC). Surgical resection remains the only curative treatment, with a success rate of only $18-25 \%$. Furthermore, not all patients diagnosed with PC are candidates for surgery, but only for palliation (1-5).

Nanotechnology represents a major subject of interest with an impact in numerous fields including biology, material sciences, chemistry, as well as medicine. The traditional treatment for PC relies mostly on chemotherapy, radiotherapy and surgery, however new research in nano-oncology shows promising results. The oncological application of nanoparticles (NPs), especially gold NPs (GNPs) has emerged as a significant therapy in the diagnosis and treatment of PC $(6,7)$.

Widely recognized as biocompatible, GNPs are still being studied as a potential treatment for different cancers, with great success (8). The aim of this review was to highlight the role that GNPs may play in the management of PC, from diagnosis to treatment. The latest studies on this topic which show how GNPs may be used to diagnose PC, but also the studies that explain the dynamics of GNPs inside the cells were summarized. Data on how GNPs induce apoptosis or cytotoxicity, both per se and in combination with other therapies and procedures were also included.

\section{Materials and methods}

An electronic literature search in the PubMed database was conducted and relevant articles published up to April 2020 containing information about the use of GNPs in PC were included. In our search the following terms were used: 'gold nanoparticles', 'pancreatic cancer', 'targeted drug therapy'. In order to write this review, data from numerous types of studies, mainly experimental, both in vitro and in vivo were collected, excluding review articles. 


\section{Overview of GNPs}

GNPs have been extensively studied for their use in the treatment of cancer. They present a considerably high interest in the medical field due to their different uses, including photothermal therapies, radiosensitization, imagistic properties and targeted drug delivery. What makes them appropriate for these applications is their optical properties. Gold represents a system which has an equal number of positive ions (which have a fixed position) and conduction electrons (free and mobile) (8). When the surface of the metal is irradiated by an electromagnetic wave, the oscillating electric fields of the wave interact with the free electrons, causing the oscillation of the surface electrons in resonance with the frequency of visible light. Free electrons are conducted by the electrical field to oscillate coherently. The collective oscillations of the free electrons are also called 'plasmons', and those of the surface electrons are called 'surface plasmons'. Surface plasmons interact with visible light forming the phenomena known as 'surface plasmonic resonance' (SPR). SPR determines the formation of strong electromagnetic fields on the surface and enhances the properties of the GNP: Absorption, scattering and the conversion of light into heat. For medical imagistic purposes GNPs of larger dimensions are preferred for their better light scattering property, whereas smaller NPs are better used in photothermal therapy due to their higher efficiency in transforming light into heat $(8,9)$. The way in which the cells internalize GNPs, their intracellular distribution in different cell compartments, as well as their toxicity are dictated by their dimensions, morphology and surface properties (10). GNPs can be designed into various shapes: Spherical, hemispherical, stellar, rods, branched as well as other shapes (10).

GNPs can be produced in large quantities, with well-established shapes and sizes. They can be also synthesized directly in situ by chemically reducing gold salts and initiating their growth by using growth-nuclei which help the NPs increase in size until the desired dimensions are reached. It has been demonstrated that this plays an important role on how the cell internalizes the NPs and also on the cytotoxic effects NPs have against the cell. The most toxic appear to be the GNPs of smaller dimensions (1-2 nm), their toxicity expressing on both malignant and healthy human cells. Larger GNPs (4.8-12 nm) present an important toxicity on cancer cells, but little toxicity on healthy cells, while GNPs which exceed $15 \mathrm{~nm}$ are considered to be non-toxic $(10,11)$.

Despite all the advantages that GNPs present, there are still some problems that must be addressed. One inconvenience is that GNPs absorb certain proteins which leads to their instability. To stop this from happening, they are usually coated with one layer of hydrophilic biocompatible polymer-like dendrimer, polylysine, PEI or polyethylene glycol. Another problem that may occur is that once they get inside the organism, they can be retained by the macrophages and other cells of the reticuloendothelial system (RES). As foreign particles are eliminated by the RES, the challenge is to prevent GNPs, once in vivo, from being internalized by RES cells in order to prolong the time they spend inside the organism. An important role in this issue is played by the size of the NPs. It has been observed that smaller-sized particles have a considerably longer life in the blood stream compared to larger NPs (11).
Their most common sites of action are the nucleus, mitochondria and the endoplasmic reticulum. At the nuclear level, GNPs work by drug toxicity, gene expression modulation or direct toxicity, while at the mitochondrial level GNPs may produce ROS, may activate autophagy or may modify the membrane potential (12).

\section{GNPs used in the treatment of PC}

GNPs present a high radio-enhancing property, which has made them a candidate for radiotherapy studies. Ivošev et al studied the uptake mechanism, internalization and excretion of GNPs with a core size of $2 \mathrm{~nm}$ and hydrodynamic diameter of $4.5 \mathrm{~nm}$ (ultra-small GNPs) functionalized with dithiolated diethylenetriaminepentaacetic acid (GNPs-DTDTPA) in several cancer cell lines (Table I). They demonstrated that the dynamics of these GNPs are dependent on the cell line, concluding that they may be a promising candidate for the treatment of PC (13). Huay et al revealed that pre-treatment of PC cells with GNPs sensitized the cells to the effects of gemcitabine, decreasing gemcitabine-induced EMT, stemness and MAPK activation (14). Another study on photodynamic therapy focused on the effects of GNPs attached on the surface of silica NPs organically modified with photosensitizer methylene blue. Irradiating these NPs with $630 \mathrm{~nm}$ resulted in an enhanced $\mathrm{O}_{2}^{-}$production, with various amounts that were dependent on the diameter of silica NPs (30/55/80 nm). A PC cell line (PANC-1) was used to study the dynamics of cellular uptake and photodynamic cytotoxicity. The study revealed that the effects were dependent on the attachment of GNPs to the surface of silica NPs, as well as to the size of silica NPs (15).

Since PC remains difficult to treat, different combined approaches are being studied. Zhang et al focused on a synergistic strategy in which honeycomb-like GNPs (HGNPs) were used together with interventional photo-thermal therapy (IPTT) combined with brachytherapy (BT) in two different types of PC cell lines (PANC-1 and SW1990). Firstly, they conducted a survival assay to evaluate the radiosensitization effectiveness of HGNPs in vitro, obtaining a higher apoptosis rate compared to cells without HGNPs. Then, they used tumor-bearing mice (SW1990) to study in vivo distribution and the effects of the NPs. They divided the mice into 5 groups, obtaining a significantly better tumor destruction in the HGNPs + IPTT and HGNPs + IPT-BT groups, with a lower rate of loco-regional recurrence in the HGNPs + IPT-BT group. Furthermore, the normal tissues appeared to present no side effects from this synergistic therapy (16).

Gold nano-cages (GNCs) have also been studied as potential treatment for PC. Qiu et al designed a theranostic NP using GNCs modified with hyaluronic acid, conjugated with anti-Glypican-1 (anti-GPC1) antibody, oridonin, gadolinium and Cy7 dye. The NPs were demonstrated to have a long-time stability and MRI and fluorescent properties, rendering them useful in the diagnosis phase of a cancer. Various cell lines (Table I) were used to study the dynamics of NPs, which were endocytosed only by PANC-1 and BXPC-3 cells, but not by 293T cells. While presenting insignificant toxicity, the designed NPs significantly promoted the apoptosis of PC cells in vitro, while in vivo they permitted multimodal imaging and targeted drug therapy (17). 
Table I. Different designs of GNPs studied in pancreatic cancer.

\begin{tabular}{|c|c|c|c|c|}
\hline Authors, year & Design of the NPs & Cell line & Results & (Refs.) \\
\hline $\begin{array}{l}\text { Ivošev et al } \\
2020\end{array}$ & $\begin{array}{l}\text {-Ultrasmall GNPs (core size } 2 \mathrm{~nm} \text {, } \\
\text { hydrodynamic diameter } 4.5 \mathrm{~nm} \text { ) } \\
\text {-Functionalized with dithiolated } \\
\text { diethylenetriaminepentaacetic acid }\end{array}$ & $\begin{array}{l}\text {-Pancreatic cancer (BxPC-3) } \\
\text {-Glioblastoma (U87-MG) } \\
\text {-Chordoma (UM-Chor1) } \\
\text {-Cervix (HeLa) } \\
\text {-Prostate (PC3) } \\
\text {-Fibroblasts (dermal fibroblasts) }\end{array}$ & $\begin{array}{l}\text {-Uptake and excretion } \\
\text { dependent on the cell line } \\
\text {-Concentrate preferentially } \\
\text { in cancer cell lines, } \\
\text { particularly in pancreatic } \\
\text { cancer, prostate cancer and } \\
\text { glioblastoma }\end{array}$ & (13) \\
\hline $\begin{array}{l}\text { Huay et al } \\
2019\end{array}$ & $-20 \mathrm{~nm}$ GNPs & $\begin{array}{l}\text {-Pancreatic cancer (PANC-1, } \\
\text { AsPC-1, MIA PaCa-2, HPAFII) }\end{array}$ & $\begin{array}{l}\text {-Pre-treatment with GNPs } \\
\text { inhibits the upregulation of } \\
\text { stem cell markers } \\
\text {-Pre-treatment with GNPs } \\
\text { reverses the epithelial } \\
\text {-Mesenchymal } \\
\text { transition, inhibits the } \\
\text { stemness induced by } \\
\text { gemcitabine and sensitizes } \\
\text { gemcitabine-resistant } \\
\text { pancreatic cancer to } \\
\text { gemcitabine }\end{array}$ & (14) \\
\hline $\begin{array}{l}\text { Roy et al } \\
2019\end{array}$ & $\begin{array}{l}\text {-GNPs attached to silica NPs } \\
\text { modified with methylene blue }\end{array}$ & -Pancreatic cancer (PANC-1) & $\begin{array}{l}\text {-Irradiation with } 630 \mathrm{~nm} \\
\text { laser } \\
\text {-Enhanced } \mathrm{O}_{2}^{-} \text {production, } \\
\text { dependent on the diameter } \\
\text { of the silica NPs }\end{array}$ & (15) \\
\hline $\begin{array}{l}\text { Zhang et al } \\
2019\end{array}$ & $\begin{array}{l}\text {-HGNPs (HGNPs) along with } \\
\text { photothermal therapy and } \\
\text { brachytherapy }\end{array}$ & $\begin{array}{l}\text {-Pancreatic cancer (PANC-1, } \\
\text { SW1990) }\end{array}$ & $\begin{array}{l}\text {-In vitro: Higher apoptosis } \\
\text { rate compared to cells that } \\
\text { were not treated with } \\
\text { HGNPs } \\
\text {-In vivo: Significantly better } \\
\text { tumor destruction in the } \\
\text { HGNPs + IPTT and HGNPs } \\
\text { + IPT-BT groups, with a } \\
\text { lower rate of locoregional } \\
\text { recurrence in the HGNPs + } \\
\text { IPT-BT group } \\
\text {-Normal tissues not affected } \\
\text { by the combined therapy }\end{array}$ & (16) \\
\hline $\begin{array}{l}\text { Qiu et al } \\
2018\end{array}$ & $\begin{array}{l}\text {-GNCs modified with hyaluronic } \\
\text { acid and conjugated with } \\
\text { anti-glypican-1 antibody, oridonin, } \\
\text { gadolinium and Cy7 dye }\end{array}$ & $\begin{array}{l}\text {-Pancreatic cancer (PANC-1, } \\
\text { BXPC-3, SW1990) } \\
\text {-human embryonic kidney } \\
\text { (293 T-cell line) }\end{array}$ & $\begin{array}{l}\text {-GNCs were endocytosed } \\
\text { only by PANC-1 and } \\
\text { BXPC-3, but not by } 293 \\
\text { T-cells } \\
\text {-In vitro: Promoted the } \\
\text { apoptosis of pancreatic } \\
\text { cancer cells } \\
\text {-In vivo: Permitted } \\
\text { multimodal imaging and } \\
\text { targeted drug therapy }\end{array}$ & $(17)$ \\
\hline
\end{tabular}

GNPs, gold nanoparticles; HGNPs, honeycomb-like GNPs; GNCs, gold nanocages; IPTT, interventional photo-thermal therapy; BT, brachytherapy; IPT-BT, interventional photothermal-brachytherapy. 
Table II. GNPs conjugated with chemotherapeutics and their effects on pancreatic cancer cells.

\begin{tabular}{|c|c|c|c|c|}
\hline Authors, year & Design of the NPs & Cell line & Results & (Refs.) \\
\hline $\begin{array}{l}\text { Coelho et al } \\
2019\end{array}$ & $\begin{array}{l}\text {-Polyethylene glycol-coated GNPs } \\
\text { conjugated with doxorubicin/varlitinib } \\
\text { (VAL-PEG-GNPs/DOX-PEG-GNPs) }\end{array}$ & $\begin{array}{l}\text {-Healthy pancreatic cells } \\
\text { (hTERT-HPNE) } \\
\text {-Pancreatic cancer cells } \\
\text { (S2-013, MIA PaCa-2) }\end{array}$ & $\begin{array}{l}\text {-PEG-GNPs up to } 1.0 \mathrm{nM} \\
\text { are not toxic } \\
\text {-DOX-PEG-GNPs are } \\
\text { toxic for MIA PaCa-2, but } \\
\text { not toxic for other cell } \\
\text { lines } \\
\text {-VAL-PEG-GNPs are } \\
\text { toxic for both MIA PaCa-2 } \\
\text { and S2-013, but not toxic } \\
\text { for hTERT-HPNE }\end{array}$ & $(23)$ \\
\hline $\begin{array}{l}\text { Steckiewicz } \\
\text { et al } 2020\end{array}$ & $\begin{array}{l}\text {-GNPs stabilized with reduced } \\
\text { glutathione and conjugated with } \\
\text { doxorubicin, gemcitabine and } \\
\text { cytarabine }\end{array}$ & $\begin{array}{l}\text {-Healthy pancreatic cells } \\
\text { (hTERT-HPNE) } \\
\text {-Pancreatic cancer cells } \\
\text { (PANC-1) } \\
\text {-Human osteosarcoma cells } \\
\text { (143B) } \\
\text {-Human osteoblast (hFOB1.19) } \\
\text {-Breast cancer cells (MCF7) } \\
\text {-Breast epithelial cells } \\
\text { (MCF10A) }\end{array}$ & $\begin{array}{l}\text {-GNPs present a cytotoxic } \\
\text { effect dependent on their } \\
\text { concentration } \\
\text {-Low impact on the healthy } \\
\text { cells }\end{array}$ & (24) \\
\hline $\begin{array}{l}\text { Banstola et al } \\
2019\end{array}$ & $\begin{array}{l}\text {-GNPs linked using polydopamine } \\
\text { to paclitaxel-loaded } \\
\text { PLGA microspheres } \\
\text { (GNPs-pD-PTX-PLGA-Ms) }\end{array}$ & $\begin{array}{l}\text {-Pancreatic cancer cells } \\
\text { (PANC-1) }\end{array}$ & $\begin{array}{l}\text {-Enhanced ROS } \\
\text { generation when using } \\
\text { NIR } \\
\text {-Downregulation of } \\
\text { CATALASE and SOD2 }\end{array}$ & $(25)$ \\
\hline
\end{tabular}

rGNPs, gold nanoparticles; NPs, nanoparticles.

\section{GNPs and targeted drug therapy in PC}

Targeted Drug Delivery (TDD) represents the most advanced mode of substance transport through which the efficacy of the active substance is enhanced in a specific area, while at the same time the effect on the healthy cells is diminished $(18,19)$. Nanotechnology has already demonstrated its efficacy in the TDD system and it has been suggested that the smaller the size of the NPs, the higher their specificity. Specific markers can be chemically modified or can be attached to the surface of the NPs in order to be able to directly interact with the cell-surface receptors and to easily penetrate the cell membrane layers (18-22).

Coelho et al evaluated the synergistic effect of two nano-conjugates [the polyethylene glycol-coated GNPs (PEG-GNPs) conjugated with doxorubicin (DOX-PEG-GNPs) and conjugated with varlitinib (VAL-PEG-GNPs) as in vitro targeted delivery against proliferation of cancer cells. In the study, a healthy pancreatic cell line (hTERT-HPNE) and two PC cell lines (S2-013 and MIA PaCa-2) were used. In the study, PEG-GNPs up to $1.0 \mathrm{nM}$ were not toxic to either cell line (incubation period of $72 \mathrm{~h}$ ). Concurrently, it was revealed that DOX-PEG-GNPs were toxic for MIA PaCa-2 cells (derived from primary pancreatic tumor), but not toxic for other cell lines. In addition, VAL-PEG-GNPs were not toxic for hTERT-HPNE, but they were toxic for both MIA PaCa-2 and S2-013 (derived from metastatic pancreatic tumors). Furthermore, the cells were treated for $24 \mathrm{~h}$ with DOX-PEG-GNPs, and then they were incubated for $48 \mathrm{~h}$ with VAL-PEG-GNPs, comparing the results with free antitumor drugs. It was concluded that the combined effect of the two antitumor drugs was only observed with the conjugates and it was higher for S2-013 cells. In addition, in the normal pancreatic cell line, the toxicity of drugs that were conjugated with PEG-GNPs was smaller compared with the toxicity induced by unconjugated free drugs (23).

Conjugating GNPs with chemotherapeutics represent a major point of interest in numerous studies (Table II). Steckiewicz et al assessed the safety and antitumor potential of GNPs stabilized with reduced glutathione (GSH) and conjugated with doxorubicin (DOX), gemcitabine (GEM) and cytarabine (CTA). The cytotoxic effect was assessed by MTT assay in vitro in different cell lines. It was revealed that GNPs presented a cytotoxic effect that was dependent on their concentration, with a lower impact on the healthy cell lines compared to the cancer cell lines, demonstrating that assessed GNPs present anticancer potential (24). 
Banstola et al developed adherent GNPs linked using polydopamine to paclitaxel-loaded PLGA microspheres (GNPs-pD-PTX-PLGA-Ms) which they further assessed with and without NIR treatment in PANC-1 cells. It was revealed that using NIR resulted in more ROS generation and also in the downregulation of levels of two important antioxidant enzymes, CATALASE and SOD2. The effect of chemo-photothermal therapy was demonstrated to be synergistic in inducing the apoptosis of cancer cells (25).

\section{Other perspectives on GNPs and PC}

There are studies that focus on the role that NPs may play in the early detection of PC or even in the reversal of pancreatic desmoplasia. Nanotechnology is also studied through the prism of cancer detection. Alarfaj et al synthesized carbon quantum dots conjugated with gold nano-composite in order to detect CA 19-9, a tumor marker used in the rapid screening of PC (26). Han et al used pegylated polyethylenimine-coated GNPs to co-deliver heat shock protein HSP47 (targeting siRNA) and all-trans retinoic acid to re-educate activated pancreatic stellate cells (PSC). It was revealed that this nano-system induced PSC quiescence and inhibited extracellular matrix hyperplasia. In this context, the delivery of the drug to the tumor was enhanced, concurrently improving the effectiveness of chemotherapeutics (27). Similarly, another study revealed that miR-21 inhibitor can be co-delivered with gemcitabine by dendrimer-entrapped GNPs for PC therapy using new ultrasound-targeted micro-bubble destruction, with significant effects (28).

In recent years, the direction of GNP development had been towards obtaining an effective targeted therapy. Although experimental designs show promising results, a perfectly designed molecule with $100 \%$ bioavailability, significant antitumoral effects, no systemic side effects and at a low price has yet to be revealed. Nevertheless, researchers are making promising advances, increasingly focusing on combining different techniques, taking advantage of all the proprieties of gold, as aforementioned. However, as technology moves forward, newly developed quantum dots are becoming increasingly prevalent, perhaps even overtaking the interest from GNPs.

\section{Conclusions}

GNPs have been demonstrated to be suitable for diagnosing PC, inducing apoptosis in these cancer cells and even making PC cells more sensitive to chemotherapeutics $(23-26,28)$. At present, the literature has limited but promising data on this topic. More studies are required in order to find the most efficient design for a GNP that can be safely used in vivo in PC patients with the intention to cure it. The studies presented in this review may be an ideal starting point for new studies to emerge that may provide more insights into this field.

\section{Acknowledgements}

Not applicable.

\section{Funding}

No funding was received.

\section{Availability of data and materials}

Not applicable.

\section{Authors' contributions}

AMT and AAA conceived the review. AMT, ALR and AAA participated in the manuscript design and gathering of data. ALR, AAA and LC performed critical revision of the manuscript. All authors read and approved the final manuscript to be published.

\section{Ethics approval and consent to participate}

Not applicable.

\section{Patient consent for publication}

Not applicable.

\section{Competing interests}

The authors declare that they have no competing interests.

\section{References}

1. Cassidy J, Bissett D, Spence RAJ, Payne M and Morris-Stiff G: Oxford Handbook of Oncology. 4th edition. Oxford University Press, New York, NY, 2015.

2. Rougier P, Legoux JL, Lepage $C$ and Michel P: Hepato-gastroenterologists and oncologists are complementary in the management of digestive cancers. Dig Liver Dis 43: 583-584, 2011 .

3. Jooste V, Remontet L, Colonna M, Belot A, Launoy G, Binder F, Faivre $\mathrm{J}$ and Bouvier AM: Trends in the incidence of digestive cancers in France between 1980 and 2005 and projections for the year 2010. Eur J Cancer Prev 20: 375-380, 2011.

4. Chauvenet M,Lepage C, Jooste V, Cottet V,Faivre J and Bouvier AM: Prevalence of patients with colorectal cancer requiring follow-up or active treatment. Eur J Cancer 45: 1460-1465, 2009.

5. Chabner BA and Longo DL: Harrison's Manual of Oncology. 2nd edition. McGraw-Hill Education, 2014.

6. Hock1 PF, Wolosiuk A, Pérez-Sáez JM, Bordoni AV, Croci DO, Toum-Terrones Y, Soler-Illia GJ and Rabinovich GA: Glyco-nano-oncology: Novel therapeutic opportunities by combining small and sweet. Pharmacol Res 109: 45-54, 2016.

7. Thakor AS and Gambhir SS: Nanooncology: The future of cancer diagnosis and therapy. CA Cancer J Clin 63: 395-418, 2013.

8. Sharma H, Mishra PK, Talegaonkar S and Vaidya B: Metal nanoparticles: A theranostic nanotool against cancer. Drug Discov Today 20: 1143-1151, 2015.

9. de Oliveira R, Zhao P, Li N, de Santa Maria LC, Vergnaud J, Ruiz J, Astruc D and Barratt G: Synthesis and in vitro studies of gold nanoparticles loaded with docetaxel. Int J Pharm 454: 703-711, 2013.

10. Kodiha M, Wang YM, Hutter E, Maysinger D and Stochaj U: Off to the organelles-killing cancer cells with targeted gold nanoparticles. Theranostics 5: 357-370, 2015.

11. Gu YJ, Cheng J, Lin CC, Lam YW, Cheng SH and Wong WT: Nuclear penetration of surface functionalized gold nanoparticles. Toxicol Appl Pharmacol 237: 196-204, 2009.

12. Ryu JH, Lee S, Son S, Kim SH, Leary JF, Choi K and Kwon IC: Theranostic nanoparticles for future personalized medicine. J Control Release 190: 477-484, 2014.

13. Ivošev V, Sánchez GJ, Stefancikova L, Haidar DA, González Vargas CR, Yang X, Bazzi R, Porcel E, Roux S and Lacombe S: Uptake and excretion dynamics of gold nanoparticles in cancer cells and fibroblasts. Nanotechnology 31: 135102, 2020. 
14. Huay Y, Zhang Y, Xiong X, Das S, Bhattacharya R and Mukherjee P: Gold Nanoparticles sensitize pancreatic cancer cells to gemcitabine. Cell Stress 3: 267-279, 2019.

15. Roy I: Gold nanoparticle-enhanced photodynamic therapy from photosensitiser-entrapped ormosil nanoparticles. J Nanosci Nanotechnol 19: 6942-6948, 2019.

16. Zhang F, Han X, Hu Y, Wang S, Liu S, Pan X, Wang H, Ma J, Wang W, Li S, et al: Interventional photothermal therapy enhanced brachytherapy: A new strategy to fight deep pancreatic cancer. Adv Sci (Weinh) 6: 1801507, 2019.

17. Qiu W, Chen R, Chen X, Zhang H, Song L, Cui W, Zhang J, Ye D, Zhang Y and Wang Z: Oridonin-loaded and GPC1-targeted gold nanoparticles for multimodal imaging and therapy in pancreatic cancer. Int J Nanomedicine 13: 6809-6827, 2018.

18. Sudimack J and Lee RJ: Targeted drug delivery via the folate receptor. Adv Drug Deliv Rev 41: 147-162, 2000.

19. Muller RH and Keck CM: Challenges and solutions for the delivery of biotech drugs-a review of drug nanocrystal technology and lipid nanoparticles. J Biotechnol 113: 151-170, 2004 .

20. Nayak D, Minz AP, Ashe S, Rauta PR, Kumari M, Chopra P and Nayak B: Synergistic combination of antioxidants, silver nanoparticles and chitosan in a nanoparticle based formulation: Characterization and cytotoxic effect on MCF-7 breast cancer cell lines. J Colloid Interface Sci 470: 142-152, 2016.

21. Chaudhury A and Das S: Recent advancement of chitosan-based nanoparticles for oral controlled delivery of insulin and other therapeutic agents. AAPS PharmSciTech 12: 10-20, 2011
22. Tomşa AM,Picos A, Picos AM and Răchisan AL: Mitochondrial nanotargeting in malignancies (Review). Exp Ther Med 20: 3444-3451, 2020.

23. Coelho SC, Reis DP, Pereira MC and Coelho MAN: Doxorubicin and varlitinib delivery by functionalized gold nanoparticles against human pancreatic adenocarcinoma. Pharmaceutics 11: $551,2019$.

24. Steckiewicz KP, Barcinska E, Sobczak K, Tomczyk E, Wojcik M, and Inkielewicz-Stepniak I: Assessment of Anti-Tumor potential and safety of application of Glutathione stabilized Gold Nanoparticles conjugated with Chemotherapeutics. Int J Med Sci 17: 824-833, 2020.

25. Banstola A,PhamTT,Jeong JHand YookS: Polydopamine-tailored paclitaxel-loaded polymeric microspheres with adhered NIR-controllable gold nanoparticles for chemo-phototherapy of pancreatic cancer. Drug Deliv 26: 629-640, 2019.

26. Alarfaj NA, El-Tohamy MF and Oraby HF: CA 19-9 pancreatic tumor marker fluorescence immunosensing detection via immobilized carbon quantum dots conjugated gold nanocomposite. Int J Mol Sci 19: 1162, 2018.

27. Han X, Li Y, Xu Y, Zhao X, Zhang Y, Yang X, Wang Y, Zhao R, Anderson G, Zhao Y and Nie G: Reversal of pancreatic desmoplasia by re-educating stellate cells with a tumour microenvironment-activated nanosystem. Nat Commun 9: 3390, 2018.

28. Lin L, Fan Y, Gao F, Jin L, Li D, Sun W, Li F, Qin P, Shi Q, Shi X and Du L: UTMD-promoted co-delivery of gemcitabine and miR-21 inhibitor by dendrimer-entrapped gold nanoparticles for pancreatic cancer therapy. Theranostics 8: 1923-1939, 2018. 